\title{
A EXPERIÊNCIA DO NÚCLEO DE ESTUDOS DA VIOLÊNCIA DA USP
}

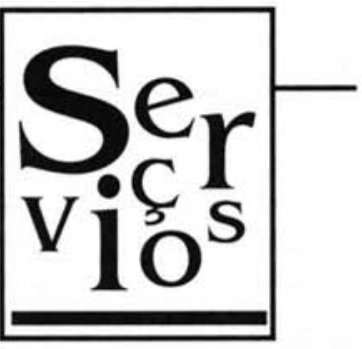

O Núcleo de Estudos da Violência da Universidade de São Paulo (NEV-USP) completa dez anos de existência. Criado em 1987 por um grupo de professores da Universidade São Paulo, foi formalmente integrado à estrutura universitária em 1990 e é hoje um dos principais centros de estudos e pesquisas na área de direitos humanos no Brasil.

Desde a sua criação, o NEV-USP tem colaborado com as autoridades governamentais na formulação e implementação de políticas de proteção e promoção dos direitos humanos, participado do debate público sobre o problema da violência, e se empenhado na defesa de pessoas e grupos vítimas de graves violações dos direitos humanos. Neste trabalho de estudo, pesquisa e prestação de serviço à comunidade, o NEV-USP tem atuado em estreita cooperação com os departamentos de Ciência Política e de Sociologia e tem recebido pleno apoio da diretoria da Faculdade de Filosofia, Letras e Ciências Humanas, da Reitoria, assim como da Pró-Reitoria de Pesquisa da USP.

$\mathrm{Na}$ defesa de vítimas de violações de direitos humanos, o NEV-USP tem trabalhado em colaboração com a Comissão Teotônio Vilela de Direitos Humanos - para a qual fornece local de funcionamento, voluntários e informações ou dados de pesquisa. O NEVUSP e a Comissão Teotônio Vilela desenvolvem ações em conjunto com organizações nacionais e internacionais de direitos humanos como o Movimento Nacional de Direitos
Humanos, Anistia Internacional, Human Rights Watch Americas, o Comitê Internacional da Cruz Vermelha, Lawyers' Committe for Human Rights e Center for Justice and International Law.

Ao participar do debate público sobre o problema da violência e dos direitos humanos - principalmente através da participação em seminários e debates, da realização de palestras, de entrevistas à imprensa $\mathrm{e}$ apresentação de resultados de pesquisa - os pesquisadores do NEV-USP têm contribuído para desmistificar as idéias, ainda presentes no Brasil, de que a luta contra a violência é incompatível com a defesa dos direitos humanos, de que os direitos humanos são direitos dos bandidos e os direitos humanos são luxos dos países desenvolvidos.

O NEV-USP combina atividades nas áreas acadêmica e cívica com objetivo de estreitar os vínculos entre a universidade e a sociedade, desenvolvendo projetos que contribuam não apenas para a compreensão mas também para a resolução dos graves problemas dos direitos humanos existentes no Brasil.

\section{O AUTOR}

Paulo de Mesquita Neto

Doutor em Ciência Política pela Universidade de Columbia, EUA. Colaborador do Departamento de Ciência Política da FFLCH-USP e pesquisador senior do Núcleo de Estudos da Violência da USP. E-mail: pmesquit@usp.br 
O NEV-USP é coordenado pelos professores Paulo Sérgio Pinheiro e Sérgio Adorno. Tem como coordenadora de pesquisas a professora Nancy Cardia e seu comitê executivo é integrado pelos professores Sérgio Adorno (Sociologia), Maria Helena Oliva Augusto (Sociologia), Rosa Maria Fischer (Economia, Administração e Contabilidade), Eduardo Kugelmans (Ciência Política), Sílvia Lesser de Mello (Psicologia) e Paulo Sérgio Pinheiro (Ciência Política). Conta, também, com uma equipe interdisciplinar de cerca de 30 pessoas, incluindo pesquisadores seniores, juniores, colaboradores e assistentes, além de uma pequena equipe administrativa.

$\mathrm{Na}$ constituição da equipe responsável por cada projeto de pesquisa, o NEV-USP realiza um processo seletivo para escolha de estudantes de graduação que possam participar do projeto como pesquisadores assistentes e receber orientação e treinamento na realização de pesquisas empíricas. Assim, nos seus dez anos de existência, o NEVUSP tem contribuído não apenas para produção e distribuição de conhecimento mas também para a formação de novos pesquisadores que possam dar continuidade ao trabalho de estudos e pesquisas iniciado por seus fundadores.

\section{PESQUISAS E DEFESA DOS DIREITOS HUMANOS}

O NEV-USP tem se dedicado a dois tipos de pesquisas, as quais podem ser caracterizadas como pesquisa pura e pesquisa aplicada. No primeiro caso, estão pesquisas cuja preocupação central é contribuir para avançar o conhecimento teórico sobre violência, direitos humanos e democracia. No segundo caso, estão pesquisas cuja preocupação central é contribuir para aprimorar as políticas de combate à violência, de proteção e promoção dos direitos humanos e de consolidação do estado de direito e da democracia no Brasil.

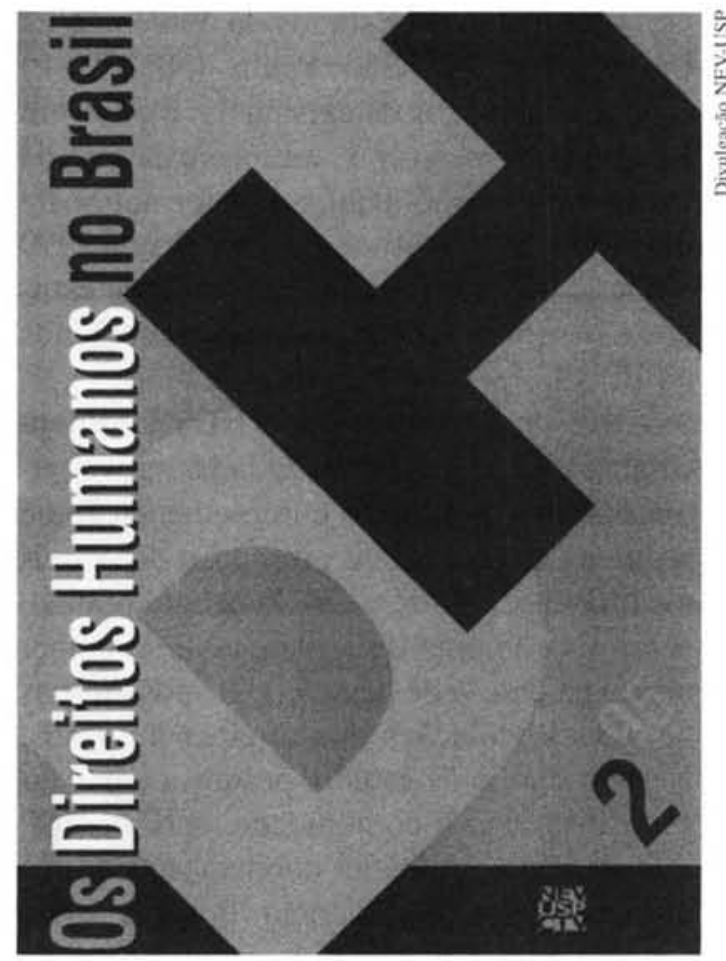

O relatório, Os direitos humanos no Brasil 1995, traz, entre outros, dados sobre a violência contra crianças e adolescentes.

$\mathrm{Na}$ linha de pesquisa pura, destaca-se a pesquisa Continuidade autoritária e construção da democracia', realizada com apoio da Fundação Ford, FAPESP e CNPq. Esta pesquisa, iniciada em 1991 e ainda em andamento, procura descrever e explicar a

1. Todos os resultados, parcial ou integralmente, das pesquisas realizadas pelo NEV-USP - inclusive as desenvolvidas com o financiamento de instituições de apoio à pesquisa, Governo Brasileiro e órgãos internacionais como a $\mathrm{ONU}$ - estâo à disposição do público, na biblioteca do NEV-USP, que funciona no período das $14 \mathrm{~h}$ às $18 \mathrm{~h}$, para consulta e/ou reprodução. 
persistência de graves violações de direitos humanos depois da transição para a democracia no Brasil.

O objetivo é identificar não apenas as principais violações de direitos humanos no país mas também os principais fatores, presentes na atuação das organizações governamentais e não-governamentais, e na cultura política brasileira, que falicitam a persistência destas violações.

No âmbito desta pesquisa, o NEV-USP constituiu e está atualizando um banco de dados sobre violência e violações de direitos humanos no Brasil, baseado em notícias dos principais jornais de São Paulo e Rio de Janeiro. Este banco de dados serviu como base para seleção de uma série de casos típi$\cos$ de violações de direitos humanos no país, os quais estão sendo estudados de maneira aprofundada para que seja feita a identificação dos principais obstáculos, nas áreas da Polícia, Ministério Público e Judiciário, para apuração e punição dos responsáveis por violações de direitos humanos.

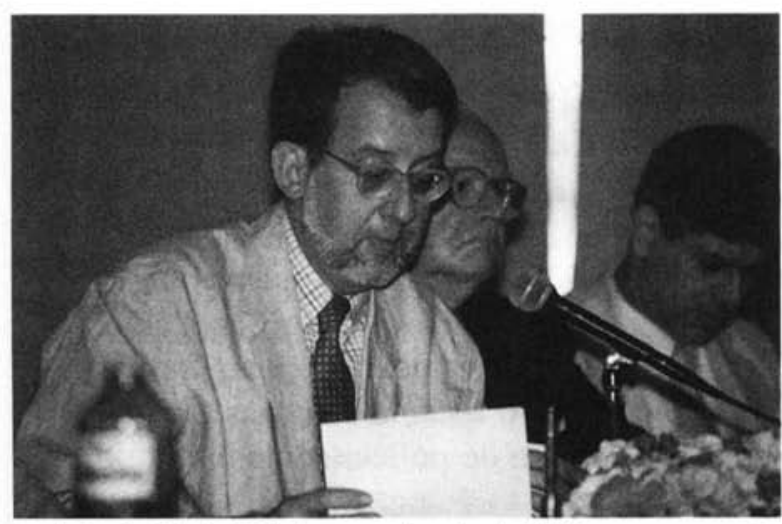

Prof. Paulo Sérgio Pinheiro, coordenador do NEV, na apresentação do relatório Direitos Humanos no Brasil 1995.

Está sendo desenvolvido também o projeto The Rockfeller Foundation
Humanities Fellowships, financiado pela Fundação Rockfeller, para estudos das relações entre democracia e direitos humanos, numa perspectiva comparada. Através deste projeto, com a duração de três anos, de 1995 a 1998, o NEV-USP está oferecendo bolsas de estudos para que pesquisadores brasileiros, estrangeiros e ativistas de direitos humanos possam vir à Universidade de São Paulo participar do grupo de trabalho da pesquisa Continuidade Autoritária e Consolidação da Democracia e desenvolver estudos sobre o tema do projeto.

Como desdobramento deste trabalho, o NEV-USP está iniciando este ano a pesquisa Democracia e Direitos: os limites da implementação institucional (1985-1995). Com apoio da FAPESP, esta pesquisa focaliza as mudanças no Executivo, Legislativo e Judiciário nos Estados de São Paulo, Rio de Janeiro, Rio Grande do Sul e Bahia desde a transição do autoritarismo para a democracia. Está sendo elaborado ainda um projeto de pesquisa sobre o papel do Judiciário na manutenção da lei e da ordem e na proteção e promoção dos direitos humanos, o qual será desenvolvido em colaboração com centros de pesquisa de outros estados do Brasil e de outros países, em particular do Rio Grande do Sul, Estados Unidos, Portugal, Argentina e Colômbia.

Outra pesquisa em andamento examina a atuação das Forças Armadas na área de segurança pública, principalmente no caso do combate ao crime organizado no Rio de Janeiro durante a Operação Rio em 1994/95. Com apoio do CNPq, este trabalho visa contribuir para aprofundar o conhecimento e o debate do papel das Forças Armadas na manutenção da lei e da ordem, na proteção dos direitos humanos e na consolidação da democracia no Brasil.

$\mathrm{Na}$ área das pesquisas aplicadas, o NEV-USP realizou em 1995/96 a pesquisa 
Direitos humanos, direito de todos, sobre as políticas de direitos humanos e os obstáculos para a proteção dos direitos humanos no Brasil. Encomendada pelo Ministério da Justiça, esta pesquisa serviu de base para o Programa nacional de direitos humanos ${ }^{2}$, lançado em maio de 1996. Na mesma linha de atuação, o NEV-USP está atualmente empenhado na realização da pesquisa Direitos humanos, direito de todos - São Paulo, encomendada pela Secretaria da Justiça e da Cidadania, cujos resultados servirão de base para o Programa Estadual de Direitos Humanos.

Num desdobramento da pesquisa Direitos humanos, direito de todos, o NEV-USP colaborou com o Ministério da Justiça e o Centro de Estudos de Cultura Contemporânea (CEDEC) na elaboração do mapa de risco de violência na cidade de São Paulo e está colaborando na elaboração de mapas de risco de violência nas cidades de Curitiba, Salvador e Rio de Janeiro.

\section{PROGRAMAS DE COOPERAÇÃO}

Em 1993-94, por solicitação do Ministério das Relações Exteriores, e com a cooperação da Fundação Alexandre de Gusmão, o NEV-USP desenvolveu pesquisa visando à preparação de três relatórios para serem apresentados pelo Governo Brasileiro à Organização das Nações Unidas: Relatório Relativo ao Pacto Internacional de Direitos Civis e Políticos; Relatório Relativo à Convenção Contra a Tortura e ou- tros Tratamentos ou Penas Cruéis, Desumanas ou Degradantes; Relatório Relativo à Convenção Internacional sobre a Eliminação de Todas as Formas de Discriminação. Em 1993, também por solicitação do Ministério das Relações Exteriores, o NEV-USP desenvolveu a pesquisa Pobreza, marginalização, violência e a realização dos direitos humanos, publicada como documento oficial da Organização das Nações Unidas para a discussão durante a Conferência Mundial de Direitos Humanos, em Viena.

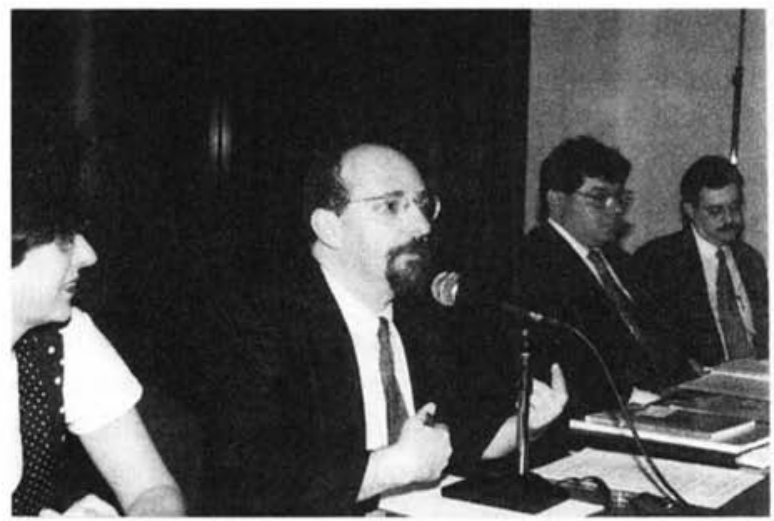

O Prof. Sérgio Adorno, coordenador do NEV, apresenta pré-Projetc do Plano Nacional de Direitos Humanos.

Desde 1996, o NEV-USP, em convênio com o Centro de Educação e Pesquisa em Direitos Humanos da Universidade de Ottawa, Canadá, realiza o Programa de Cooperação Técnica e de pesquisa entre as Universidades de Ottawa e de São Paulo, com o objetivo de estudar e propor formas de implementar o sistema de penas alternativas e o sistema de polícia comunitária no Brasil.

2. Para saber mais sobre os resultados desse estudo, consultar: BRASIL, Presidência. Programa Nacional de Direitos Humanos. Brasília: Presidência da República/Secretaria de Comunicação Social/Ministério da Justiça, 1996. 41p. Cópias desta publicação poderão ser solicitadas à: Presidência da República, Secretaria de Comunicação Social, Esplanada dos Ministérios - Bloco A - $6^{\circ}$ andar - CEP 70054-900. Brasilia - DF. 
Em convênio com a Comunidade Européia, desenvolve, também, um projeto de estudo e planejamento de reformas do processo de formação de profissionais do sistema de justiça e segurança pública, em particular os policiais, promotores públicos e juízes.

O objetivo é implantar um sistema de formação de profissionais que valorize o respeito à lei e à defesa dos direitos dos cidadãos pelos profissionais que trabalham nas áreas da justiça e da segurança pública.

Dentro da Cidade Universitária, com apoio do Instituto Ayrton Senna, o NEVUSP desenvolve o projeto Crianças e adolescentes em situação de rua: o caso da Cidade Universitária. Este projeto é um estudo das crianças e adolescentes que vivem e/ou trabalham na região da Cidade Universitária e tem como objetivo avaliar e,

Resumo: O Núcleo de Estudos da Violência (NEV-USP) completa dez anos e tem dado significativa contribuição à sociedade através de suas pesquisas e estudos acadêmicos relativos à violência, direitos humanos e o estado de direito no Brasil. O NEV atua em colaboração com a Comissão Teotônio Vilela de direitos humanos além de coordenar inúmeros projetos de pesquisa em colaboração com entidades e órgãos governamentais nacionais e internacionais.

Palavras-chave: Núcleo de Estudos da Violência, direitos humanos, violência, pesquisa, democracia eventualmente, reformular as políticas e programas de ação, de iniciativa pública e privada, que visam melhorar as condições de vida destas crianças e adolescentes.

Informações mais detalhadas sobre as atividades do NEV-USP podem ser encontradas nos relatórios Direitos humanos no Brasil, e Direitos humanos no Brasil 2, publicados em 1993 e 1995 respectivamente, e no relatório Núcleo de Estudos da Violência: cinco anos de pesquisa em Ciências Sociais, Polícas Públicas e Direitos Humanos, 1990-1995, publicado em 1996.

O NEV-USP está situado à Rua do Anfiteatro, 181 - Sala 11, Cidade Universitária, CEP 05508-900, São Paulo SP, Brasil. Na Internet, o endereço do NEV-USP é http://www.usp.br/nev Para contato, o telefone é (011) 818-3577, o fax é (011) 818-3158 e o E-mail: nev@org. usp.br.

Abstract: The "Núcleo de Estudos da Violência" (Center for the Study of Violence CSV) at University of São Paulo (USP), recently completed ten years of existence and it has contributed in an important way to society through research and academic studies on violence, human rights and the state-oflaw in Brazil. The CSV works together with the Teotônio Vilela's Commission for Human Rights, in addition to coordinating inumerous joint research projects with national and international government institutions.

Key-words: Núcleo de Estudos da Violência (Center for the Study of Violence), human rights, violence, research, democracy 